\title{
A REVIEW: DESIGN AND DEVELOPMENT OF MANUALLY OPERATED MOSQUITO REPELLENT COIL MAKING MACHINE
}

\author{
Ravi M. Sharma' ${ }^{1}$ P. B. Khope ${ }^{2}$, A. S. Nilewar ${ }^{3}$ \\ ${ }^{1}$ Student, Department of Mechanical Engineering, Priyadarshini College of Engineering, Nagpur \\ ravisharma2190@gmail.com \\ ${ }^{2}$ Assistant Professor, Department of Mechanical Engineering, Priyadarshini College of Engineering, Nagpur \\ khopepb@yahoo.co.in \\ ${ }^{3}$ Assistant Professor, Department of Mechanical Engineering, Priyadarshini College of Engineering, Nagpur
}

\begin{abstract}
This paper presents design and development of mosquito repellent coil making machine. Mosquitoes are one of the very harmful insect to mankind. Mosquitoes grows everywhere in tropical and subtropical region. With the growth of population, mosquito repellents have emerged as most useful tools in household for preventing mosquito spread diseases. Indian villages and tribal community uses their own techniques as mosquito repellents which are unhazardous to human health while chemical based repellents available in market have side effects on human health. Mosquito coils are the cheapest mosquito repellent available. Manufacturing of mosquito repellent coils require a numbers of processes and its machinery whose cost goes very high depending upon production. This bulk investment is not feasible for development of small scale industries. The purpose of this machine is to manufacture mosquito coils using simple machine with other considerations such as cost, size and easy handling. So there is need of development of such machine which is feasible for small scale industries. This machine design is based on spring lever mechanism with mosquito coil mold for manufacturing of mosquito coils. This machine can play active role for development of rural India
\end{abstract}

Keywords: Mosquito Coil, Mosquito Repellents, Rural India, Small Industries, Spring -Lever Mechanism.

\section{INTRODUCTION}

Mosquitoes are one of the most harmful insect to mankind. Mosquitoes grows every place where environment is not kept clean, neat and tidy. Control of mosquito is something of utmost importance in the present day with rising number of mosquito India bears a huge burden of mosquito borne diseases, contributing 34 per cent of global dengue and 11 per cent of global malaria cases. Population of India is increasing rapidly, deforestation and industrialized farming are also two of the factor causing an alarming increase in the range of mosquitoes. The World Health Organization says global warming is also expanding the range of mosquitoes that carry malaria, yellow fever, and dengue fever, putting millions more human at risk.

Most of Indian villagers and tribal peoples uses their own techniques for mosquito repellents such as cattle dung, neem leaves, etc. these are herbal and natural way for prevention from mosquitoes. These natural and herbal techniques are unhazardous for both environment and human health because they are chemical and toxic free. For development of rural India, their mosquito repellent techniques can play big role along with a simple low cost, easy to handle coil making machine. This can lead to better financial and economic development of rural India, also can encourage rural people to develop their small industries in other areas of manufacturing. Present mosquito repellent coil making machine are very costly, also this machine require different power sources for working. Due to cost and other requirements, this machine is not feasible for development of small industries and starting of small industries in area of mosquito repellent. Mosquito repellent coil making machine should be small in size and easy to handle.

\section{MOSQUITO REPELLENT COIL MAKING} MACHINE

Mosquito repellent coil making machine use today in mosquito repellent coil manufacturing industries like Mortein, Maxo, Good-Night etc. are costly, operates using different power sources. Size of machine used is depends on number of coil molds used in machine to fulfill demand.

Existing machines used in mosquito coil industries consists of combination of different operational machines like dry blending machine, kneading machine, extruding machine, stamping machine and dryer. These different machines uses different power sources like electrical motors, and hydraulics. These machines are good for manufacturing in large scale for large scale industries. Mosquito coil mold used are of different shape and size like spiral coils, rectangular coils, hexagonal coils etc. 


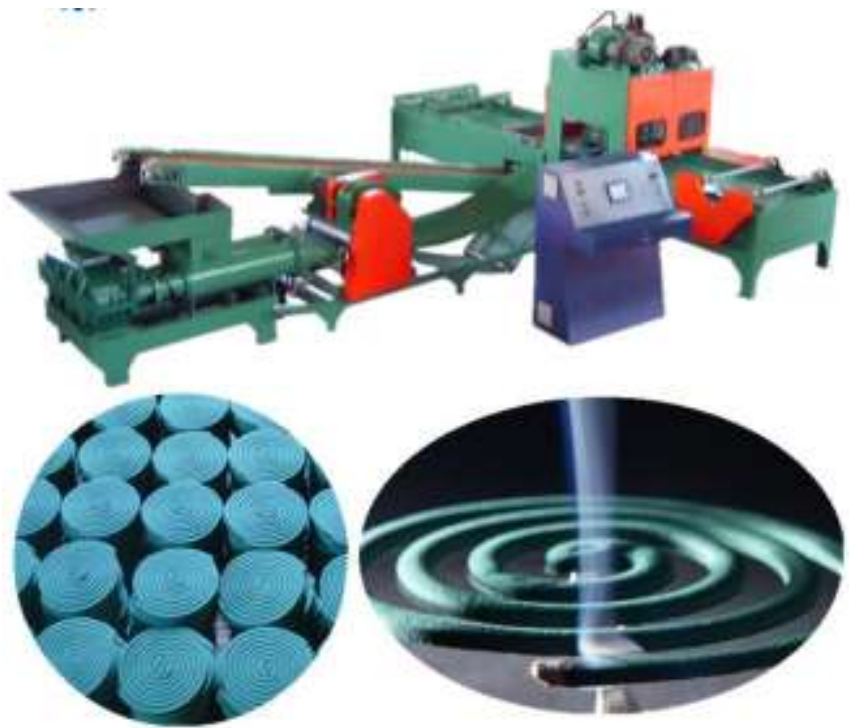

Fig.1. Existing Mosquito repellent coil making machine

Dry blending machine is used to blend all the ingredients into fine powder. Kneading machine is use to make dough by mixing it with oils and water. Extruding machine is use to extrude this dough into plain sheet of thickness $3 \mathrm{~mm}$. This sheet is fed to stamping machine using belt conveyor for making coils. Stamping machine consists of number of mosquito coil molds. These all machines combine to make one machine to make mosquito repellents coils.

\section{RELATED STUDY}

Current population of India is 1.31 billion, and increasing continuously. Hence deforestation is also increasing causing serious environmental problems. Because of bad sewage systems in India and polluted water bodies, mosquito growth is also increasing with serious diseases like malaria, dengue, chiken-gunea, etc.

\section{A. Paul Robbins, University of Arizona}

University of Arizona has conduct research on impact of climate change on mosquitoes has revealed that mosquitoes populations will increase, as well as experience changes in geographic location and season. Paul Robbins and colleagues at the University of Arizona are studied mosquitoes through computer modelling and direct trapping. They concluded that higher temperatures will facilitate an increase in mosquito population during the spring and fall seasons while higher temperature in summer will decrease mosquito population. Hence demand for mosquito repellents is increasing with increase in population, deforestation, and climate change.

\section{B. E.K. Patel et.al. "A review on Mosquito Repellent}

\section{Methods"}

According to E.K. Patel et.al. "A review on Mosquito Repellent Methods" natural mosquito repellents were preferred over chemical mosquito repellents. Chemical mosquito repellent have remarkable safety profile but they are toxicity against the skin and nervous system. Different repellents were reviewed both chemical and natural repellents, they concluded that, chemical repellents causes eye irritation, and worse problems if synthetic repellents are used such as rashes, swelling, low blood pressure, dizziness and severely irritate skin.

\section{Susheela Paanisami et.al. "Development of eco friendly mosquito repellent"}

According to SusheelaPaanisami et.al. "Development of ecofriendly mosquito repellent" formulation of eco-friendly, herbal mosquito repellent is safe, cheap, easy to use and has maximum repellence against mosquitoes, in addition to this, these mosquito repellent is less harmful to our health than the ones available in the market.

\section{S A Mandavgne et.al. "Development of cow dung \\ based herbal mosquito repellent'Equations}

S AMandavgne et.al. "Development of cow dung based herbal mosquito repellent" make an attempt to prepare a $100 \%$ herbal mosquito repellent based on traditional practices and rural wisdom. Based on survey conducted on 100 people of different social sections, they proposed optimum composition of raw material for preparation of mosquito repellent. This composition is being use by GovigyanAnusandhan Kendra, Deolapar, Disst. Nagpur.

According to report "High level committee on SocioEconomic, health and education of Tribal communities of India 2014" by Indian government, economic and financial status of people are low, most of the tribal people still lives on natural sources. For development of tribal area and tribal people, Mosquito repellent coil making machine can play a little role for development of rural India. Also their natural mosquito repellent can be useful for human life. There is need to develop rural India for development of India. This can be done by encouraging Indian villagers to develop their natural resources and to start small industries using these resources. For their development, machines required should be develop such that rural people can use it efficiently, and easily. Out of all mosquito repellents methods, mosquito coils are the cheapest method available to India and other Asian and African region. For manufacturing of mosquito coils, mosquito coil stamping machine should be developed.

Different types of mosquito repellents are used such as mosquito coils, mosquito sprays, mosquito fogs, creams, etc. These are all chemical based repellents, they are effective as mosquito repellent but they are harmful to human health. These chemical based mosquito repellents have Pyrethroids chemical which act as mosquito repelling agent. A research on Pyrethroids from Journal of Toxicology, proved that use of Pyrethroid as a repellents leads to hyper excitation of nervous system and prolong uses results in corneal damage, 
liver damage and asthma. About $12 \%$ of users are seriously affected by use of these chemical repellents. The common problems are caused by inhalation of these toxic smoke.

Indian villagers and tribal people uses their own techniques as mosquito repellent. They uses herbal or natural insecticides such as neem leaves, cintronella leaves and cow dung, etc. These methods are environment friendly.

\section{MANUALLY OPERATED MOSQUITO REPELLENT COIL MAKING MACHINE}

Existing machines cost is high and not feasible for small scale industries. For development of small industries and tribal area peoples, such where power shortages are frequent, this machine should works on manual power and size of machines should be feasible for easy handlings. Out of all the operational machine processes, only stamping operation requires coil mold and other operations can be done separately. This machine works on simple spring lever mechanism with mosquito coil mold to make stamp on sheet of repellent material. Manual effort need to stamp one double coil operation is minimum and lies below average power in human biceps i.e. 75 watt. Selection of mosquito coil mold is based on shape of coils to manufacture such as spiral coil, rectangular coil, etc. to manufacture spiral coil mold, material selected is mild-steel. With coil ejection system using spring and ejecting plate of spiral coil shape.

\section{CONCLUSION}

Design \& development of manually operated mosquito repellent coil making machine is revived. We conclude that for development of rural India, mosquito repellent coil making machine can play a role for upgrading of peoples financial as well as economic status of rural area. There is need to develop existing machine into the machine that rural people can afford, use and handle easily. Use of their natural mosquito repellent method can play a big role in human safety against mosquitoes without any side effects.

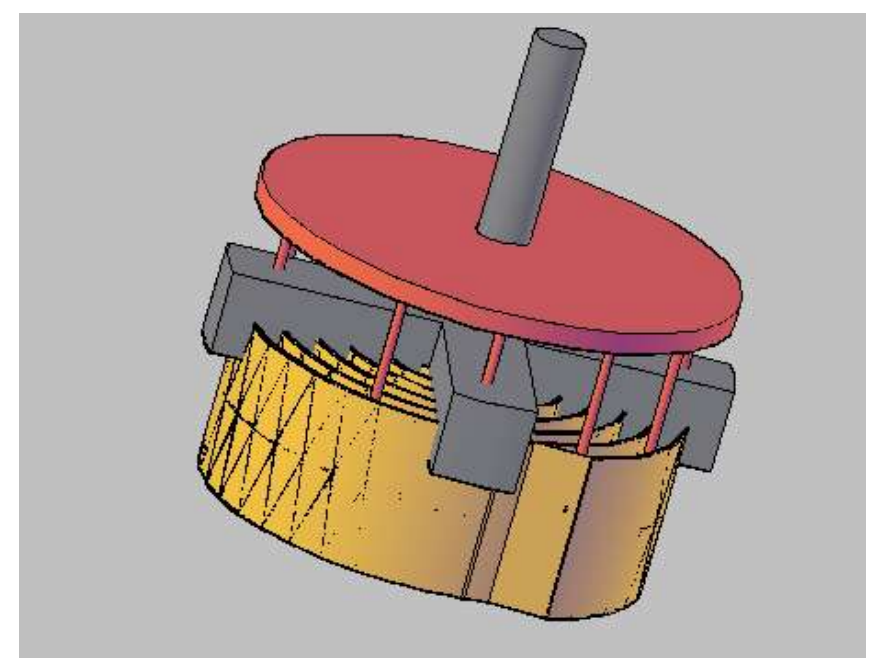

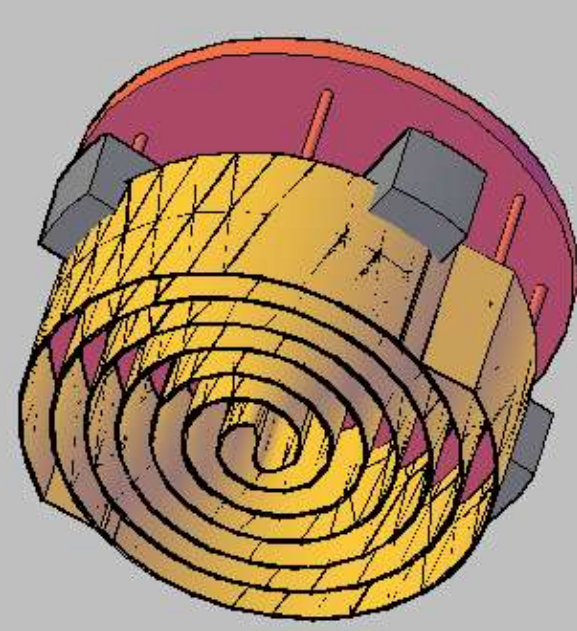

Fig.2. Mosquito coil mold spiral shape.

\section{REFERENCES}

[1] EK Patel, A. Gupta and RJ. Oswal, A review on: Mosquito Repellent Methods,IJBCBS 2012,2(3),310-317.

[2] Sah ML, Mishra D, Sah SP and Rana M, Formulation and Evaluation of Herbal Mosquito Repellent Preparations, Indian Drugs.2010;47(4);45-50

[3] Mishra AK, Singh N and Sharma VP, Use of Neem oil as a mosquito repellent in tribal villages of mandla district, Madhya Pradesh, Indian J Malariol.1995;32(3):99-103.

[4] Jeong-Kyu Kim, Chang-Soo Kang, Jong-Kwon Lee, Young-Ran Kim and Hye-Yun Han. Evaluation of Repellency effect of two Natural Aroma MosquitonRepellent Compounds, Cintronella and Cintronellal, Entomological Research. 2005;35(2):117-120.

[5] Susheela Palanisami, Ezhili Natranjan, Radha Rajamma, Development of Eco-friendly Herbal Mosquito Repellent, Journal of Innovative Biology, September 2014 Vol. 1, Issue3,P.132-136. 